\title{
LA MELODIA DE LA MEUA VIDA: \\ PER UNA EDUCACIÓ HOLÍSTICA
}

LA MELODÍA DE MI VIDA:

POR UNA EDUCACIÓN HOLÍSTICA

THE MELODY OF MY LIFE: A HOLISTIC EDUCATION

Irma Balduque Soto*

Olalla Millán Blasco*

Doi: 10.7203/anuari.psicologia.16.2.165

\begin{abstract}
Resum
Amb aquest article es vol mostrar com a través del projecte «La melodia de la meua vida» es poden posar en pràctica els postulats d'una educació holística. Aquest projecte aglutina diferents teories creant-se un teixit interrelacionat i encaminades a una mateixa meta: el desenvolupament integral de l'alumnat. Valora i fomenta el subjecte en totes les dimensions, atenent els seus potencials, és a dir, les seues intel-ligències múltiples, les seues fortaleses personals i habilitats socioemocionals. Aquest projecte dota l'alumnat d'una sèrie d'estratègies i eines per al seu autoconeixement, el del seu ambient i el paper que té en l'entorn des d'una responsabilitat social.
\end{abstract}

Paraules clau: educació holística, intel-ligències múltiples, fortaleses personals, habilitats socioemocionals.

* Titulades de magisteri per la Universidad de Zaragoza. Correspondència: <irma. balduque@gmail.com>; <olallamillan@hotmail.com>. 


\title{
Resumen
}

Con este artículo se pretende mostrar cómo a través del proyecto «La melodía de mi vida» se pueden poner en práctica los postulados de una Educación Holística. Este proyecto aglutina diferentes teorías creándose un tejido interrelacionado y encaminadas a una misma meta: El desarrollo integral del alumnado. Valora y fomenta al sujeto en todas sus dimensiones, atendiendo a sus potenciales, es decir, a sus Inteligencias Múltiples, sus Fortalezas Personales y Habilidades Socioemocionales. Este proyecto dota al alumnado de una serie de estrategias y herramientas para su autoconocimiento, el de su ambiente y el papel que desempeña en el entorno desde una responsabilidad social.

Palabras clave: educación holística, inteligencias múltiples, fortalezas personales, habilidades socioemocionales.

\begin{abstract}
This article intends to xou how the project «The melody of my life» («La melodia de la meua vida») puts in practice the principles of Holistic Education. The project combinis several theories, creating a interwoven roadmap with one goal: the integral development of the student. Multiple Intelligences and Personal and Social Competencies llauri recognized and improved and the project provides students with a set of strategies and tools for self-knowledge, understanding of the surroundings, and understanding what social responsibility they have in society.
\end{abstract}

Key words: holistic education, multiple intelligences, personal competencies, social competencies.

\section{Introducció}

Què significa per a nosaltres l'educació holística? L'entenem com l'educació compromesa en el desenvolupament de cadascun dels àmbits que conformen una persona, és a dir, el fisicocorporal, l'emocional, el social, l'intel·lectual i l'espiritual. En contemplar l'alumne des d'una òptica completa i transpersonal, amb cadascuna de les nostres actuacions, pensaments, emocions i sentiments intentarem facilitar-li una educació més integral, sense posar l'èmfasi exclusivament en la part racional.

L'objectiu d'aquest article és donar a conèixer una experiència pràctica amb la finalitat d'aportar a l'educació un model sistematitzat en l'organització escolar. 


\section{Objectiu del projecte}

L'objectiu d'aquest projecte és acostar la visió holística a l'educació. La nostra pretensió és acompanyar l'alumne i l'alumna en el seu desenvolupament integral centrant-nos en totes les seues dimensions (física, intel-lectual, socioemocional i espiritual) estant totes elles connectades i formant un tot (hólos).

En la pràctica educativa s'ha concretat i estructurat en altres dos projectes relacionats i interconnectats: El llenguatge musical i Sintonitze la meua ràdio. El primer té per objectiu primordial potenciar la comunicació de l'alumnat, així com les intel-ligències múltiples i les fortaleses personals; i el segon té per prioritat el desenvolupament d'habilitats i competències socioemocionals en l'alumnat. Les raons de parcel·lar el projecte són, d'una banda, poder-lo integrar en unes determinades àrees curriculars, i de l'altra, facilitar a l'alumnat la presa de consciència de les seues capacitats, habilitats i competències.

\section{Fonamentació teórica}

En advocar per una educació holística s'està apostant pel que defineixen R. Miller (1997) i J. P. Miller (1996):

R. Miller (1997) En l'educació holística es tenen en compte totes les facetes de l'experiència humana, no solament l'intel-lecte racional i les responsabilitats de vocació i ciutadania, sinó també els aspectes físics, emocionals, socials, estètics, creatius, intuïtius i espirituals innats de la naturalesa de l'ésser humà...

J. P. Miller (1996) L'educació holística es basa en el principi d'interconnectivitat. D'aquesta manera, busca desenvolupar aproximacions a l'ensenyament i l'aprenentatge que fomente les connexions entre matèries i entre aprenentatges a través de diverses formes de comunitat. També busca un equilibri dinàmic en situacions d'aprenentatge, entre elements com ara el contingut i el procés, l'aprenentatge i l'avaluació, i el pensament analític i el creatiu. Finalment, l'educació holística és inclusiva en el sentit d'incloure un ventall ampli de tipologies d'estudiants i una diversitat d'aproximacions d'aprenentatge, tractant d'atendre les seues diverses necessitats d'aprenentatge (Yus, 2001, 25).

Tenint com a punt de referència els quatre quadrants descrits per Ken Wilber (Wilber, 1997), a través d'aquest projecte (La melodia de la meua vida), gradualment l'alumne es va aproximant a cadascun d'ells amb la finalitat d'oferir una educació plena, equilibrada i integral. 


\begin{tabular}{|c|c|c|}
\hline I & INTERIOR & EXTERIOR \\
\hline $\begin{array}{l}N \\
D\end{array}$ & SUBJECTIU & OBJECTIU \\
\hline I & Veracitat & Veritat \\
\hline $\begin{array}{l}\text { V } \\
\text { I }\end{array}$ & Sinceritat & Correspondència \\
\hline $\mathrm{D}$ & Integritat & Representació \\
\hline $\begin{array}{l}\mathrm{U} \\
\mathrm{A}\end{array}$ & Honradesa & Proposicional \\
\hline $\mathrm{L}$ & Jo & Allò \\
\hline $\mathrm{C}$ & Nosaltres & Allò \\
\hline $\mathrm{O}$ & Rectitud & Ajust funcional \\
\hline $\begin{array}{l}\text { L'L } \\
\text { E }\end{array}$ & Ajust cultural & Xarxa de la teoria sistèmica \\
\hline $\mathrm{C}$ & Comprensió mútua & Funcionalisme estructural \\
\hline $\begin{array}{l}\mathrm{T} \\
\mathrm{I}\end{array}$ & Justícia & Teixit del sistema social \\
\hline $\mathrm{U}$ & INTERSUBJECTIU & INTEROBJECTIU \\
\hline
\end{tabular}

Figura 1. Els quatre quadrants de Ken Wilber (Wilber, 1997, p. 152).

Aquest projecte també recull el postulat de l'informe a la Unesco de la Comissió Internacional sobre l'educació per al segle XXI: «L'educació com un tot», on els quatre puntals de l'educació són: aprendre a conèixer; aprendre a fer; aprendre a viure junts, aprendre a viure amb els altres; i aprendre a ser (Delors, 1996, p. 9).

La raó principal per la qual treballem des de les intel-ligències múltiples és perquè, com diu Howard Gardner (1987),

És de summa importància que reconeguem i alimentem totes les intelligències humanes $i$ totes les combinacions d'intel-ligències. Tots som tan diferents en part perquè tots posseïm combinacions diferents d'intel-ligències. Si reconeixem aquest fet, crec que almenys tindrem més possibilitats d'afrontar adequadament els nombrosos problemes que se'ns plantegen en aquesta vida (Armstrong, 2006).

En ajustar la resposta educativa a la teoria de les intel-ligències múltiples proporcionem als alumnes un model d'aprenentatge més personal en el qual el professor coneix amb més detall la realitat de l'estudiant. A més aconseguim una major motivació, un aprenentatge més complet i real on els alumnes aprenen a ser més conscients de les seues fortaleses i febleses així com es potencien les seues habilitats i destreses. 


\section{Metodologia}

En el curs escolar 2014-2015 s'ha engegat un projecte (La melodia de la meva vida) en una aula de tercer d'ensenyament primari d'una escola pública d'ensenyament infantil i primari de Saragossa, aprofitant la conjuntura que tutora i especialista en pedagogia terapèutica intervenien en aquesta classe. És un grup format per catorze infants, dels quals deu són d'ètnia gitana i quatre que s'han incorporat al sistema educatiu espanyol tardanament lloc que provenen d'altres països. Aquests infants viuen una realitat dura i amb dificultats a nivell social, cultural, familiar, emocional i econòmic. El procés d'ensenyament-aprenentatge és condicionat al seu entorn.

Aquest projecte afavoreix el que puguem atendre aquesta diversitat potenciant no solament el rendiment acadèmic sinó també el desenvolupament psicològic de l'infant.

A més dels objectius especificats per a cadascun dels projectes, s'ha procurat que l'alumne s'endinse en el seu propi coneixement intern i comence a identificar com influeix la seua manera de pensar, de sentir i d'actuar en la relació amb els companys i companyes, així com en l'entorn més pròxim. A més s'estableix una nova relació a l'aula per generar un espai social on els estudiants desenvolupen una responsabilitat de la seua autogestió.

\section{El llenguatge musical}

Partint del postulat dels lingüistes transformacionalistes es vol en última instància que l'alumnat, progressivament, vaja descobrint el seu propi «llenguatge musical»; és a dir, que siguen cada vegada més conscients de com representen el món i com comuniquen als altres aquesta representació.

En l'àmbit curricular, l'origen d'aquest treball sorgeix de la necessitat de potenciar en l'alumnat la seua competència lingüística i s'ha desenvolupat dins el projecte de centre.

En plantejar-nos com treballar la competència lingüística, es va partir que aquesta no pot ser treballada de forma aïllada sense tenir present cadascuna de les vuit intel-ligències múltiples que va definir Howard Gardner (Gardner, 1994). Per això es van plantejar al llarg del curs escolar set tasques que persegueixen una finalitat comuna. Cadascuna d'aquestes és composta per una sèrie d'activitats les quals incideixen en el desenvolupament de les intel-ligències múltiples, ja que «cap intel-ligència no existeix per si sola en la vida real. Les intel-ligències sempre interactuen entre si» (Armstrong, 2006, p. 32).

A més, quan s'engeguen, l'alumnat està desenvolupant determinades fortaleses personals de les vint-i-quatre existents (Seligman, 2003, cap. 8-9) per afavorir el potencial de cadascun d'ells i contribuir a una vida plena. 
Aquests dos puntals fonamentals en què se sustenta aquest projecte (intelligències múltiples i fortaleses personals) estableixen una relació bidireccional, ja que estan connectats de forma natural i junts cobren sentit complet.

Aquesta figura 2 mostra un exemple de tasca (La ràdio) i com totes les intel-ligències múltiples estan relacionades entre elles i connectades amb les fortaleses personals.

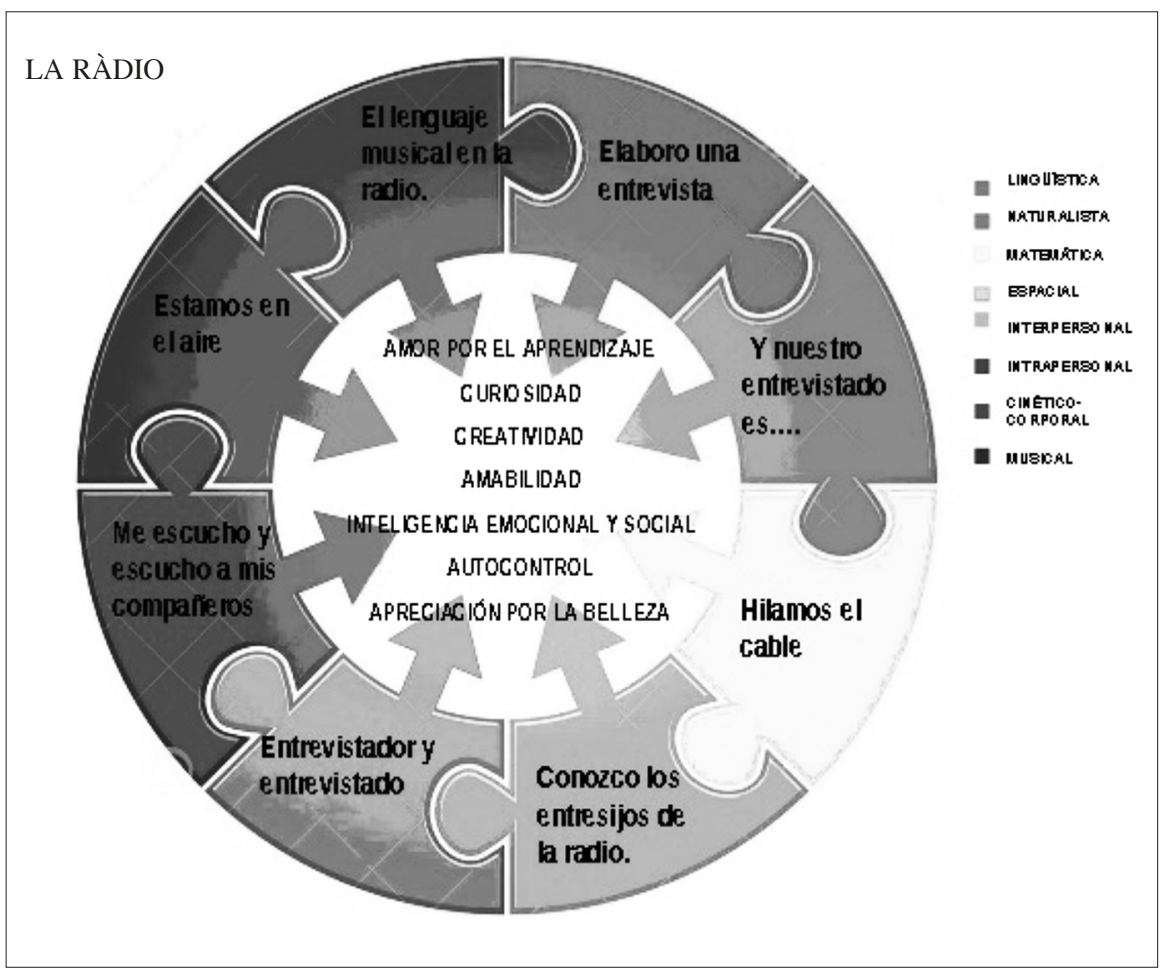

Figura 2. Projecte El llenguatge musical: Plantilla d'activitats per tasques.

En cadascuna de les activitats s'han fixat uns objectius curriculars relacionats amb cadascuna de les intel-ligències múltiples.

La metodologia aplicada ha estat l'aprenentatge cooperatiu. D'aquesta manera es proporciona el nivell motivacional necessari per activar l'aprenentatge. A través dels equips heterogenis s'afavoreix, d'una banda, la cohesió de l'equip, la seua gestió i les relacions personals entre els integrants; i de l'altra, s'afavoreix l'acceptació, el respecte, la tolerància i l'autoconeixement personal. A més es fomenta el sentit de la responsabilitat i de treball cooperatiu; així com es crea un espai on l'alumne desplega les habilitats comunicatives. 


\section{Sintonitze la meua ràdio}

Dins el creixement personal de l'alumne hi ha el desenvolupament socioemocional. Aquest projecte va encaminat a acompanyar l'alumnat en aquest desenvolupament, aço és, facilitar a l'alumnat «competències emocionals: consciència emocional, regulació emocional, autogestió, intel·ligència interpersonal, habilitats de vida i benestar» (Bisquerra, http://www.rafaelbisquerra.com/ es/educacion-emocional.html, 1 de juliol de 2015). D'aquesta manera, poden tenir un coneixement més profund d'ells mateixos i dels altres, adaptar-se i afrontar de manera més equilibrada i harmònica les diverses exigències de l'ambient i per tant, també, avançar en el seu procés d'aprenentatge.

Aquest desenvolupament socioemocional està estretament relacionat amb la intel-ligència interpersonal i intrapersonal; així com el desenvolupament de les fortaleses personals. Per tant, un projecte es nodreix de l'altre i viceversa. Tots dos es complementen i es generen sinergies.

El disseny i l'elaboració de «Sintonitze la meua ràdio» s'ha basat en les competències emocionals per les quals advoca Rafael Bisquerra i GROP (Bisquerra http://www.rafaelbisquerra.com/es/educacion-emocional.html). Partint d'ací, de manera seqüenciada, s'han creat una sèrie d'activitats ajustades a les característiques de l'alumnat.

La finalitat és que l'alumne vaja integrant una sèrie de competències socioemocionals que siguen vàlides perquè en prengueu coneixement personal, desenvolupament i adaptació a l'entorn, procurant que progressivament en siga més conscient i prenga consciència de la rellevància que té en el seu desenvolupament integral.

En concret, el curs escolar 2014-2105 s'ha començat a treballar alguns dels continguts de les competències emocionals definits per Bisquerra i que més avall s'exposa en la figura 3 .

Cadascuna de les activitats dissenyades recull els continguts abordats de forma ascendent, de manera que, quan es treballa un determinat contingut, implícitament l'alumne disposa de totes les estratègies apreses. A més d'aquestes competències emocionals detallades anteriorment es van abordant de manera natural i contínua les altres competències emocionals definides per Rafael Bisquerra, que s'abordaran els pròxims cursos. 


\begin{tabular}{|c|c|c|}
\hline & CONTINGUTS & ACTIVITATS \\
\hline \multirow{3}{*}{$\begin{array}{c}1 . \\
\text { CONSCIÈNCIA } \\
\text { EMOCIONAL }\end{array}$} & $\begin{array}{l}\text { Presa de consciència de les pròpies } \\
\text { emocions. }\end{array}$ & $\begin{array}{l}\text { Elaboració del Power Point de les } \\
\text { emocions primàries. }\end{array}$ \\
\hline & Donar nom a les pròpies emocions. & $\begin{array}{l}\text { Diari sobre les emocions } \\
\text { Registre setmanal de les emocions. }\end{array}$ \\
\hline & $\begin{array}{l}\text { Comprensió de les emocions dels } \\
\text { altres. } \\
\text { Pensaments que es generen o que } \\
\text { generen una emoció determinada. }\end{array}$ & $\begin{array}{l}\text { «Oca-emociona't». } \\
\text { El joc de les «peli-emociona't» } \\
6) \text { «Detecta-emocions» }\end{array}$ \\
\hline $\begin{array}{c}2 . \\
\text { REGULACIÓ } \\
\text { EMOCIONAL }\end{array}$ & $\begin{array}{l}\text { Prendre consciència de la interacció } \\
\text { entre emoció, pensament i compor- } \\
\text { tament. } \\
\text { Expressió emocional. } \\
\text { Capacitat de regulació emocional. } \\
\text { Habilitats d'afrontament. }\end{array}$ & $\begin{array}{l}\text { 7) L'activitat } 6 \text { serveix per al primer } \\
\text { punt. } \\
\text { 8) Incongruent-congruent. } \\
\text { 9) Role-playing d'emocions primà- } \\
\text { ria, Com les expresso? Quin pinso? } \\
\text { 10) Tècniques de relaxació. } \\
\text { 11) Laberint en el meu cap. }\end{array}$ \\
\hline $\begin{array}{c}3 . \\
\text { AUTONOMIA } \\
\text { PERSONAL }\end{array}$ & Autoestima. & $\begin{array}{l}\text { Paperets a l'esquena. } \\
\text { «Carta-emociona't» }\end{array}$ \\
\hline
\end{tabular}

Figura 3. Projecte: «Sintonitze la meua ràdio: basat en les competències emocionals de Bisquerra. Relació de continguts amb activitats elaborades el curs 2014-2015».

\section{Resultats}

Amb cada activitat realitzada, els alumnes anaven valorant a través d'un registre escrit el seu treball personal i el seu treball en equip. D'aquesta manera, els alumnes mateixos podien anar veient l'evolució del seu grup al llarg del curs. A més, entre tots dedicàvem algun temps a reflexionar sobre aquestes qüestions. Així mateix, les professores anàvem apreciant un canvi d'actitud i compromís cap a l'aprenentatge que es reflectia positivament en els resultats acadèmics. Amb aquesta millora, els alumnes han après a autogestionar-se i a tolerar els seus companys. El fet d'afrontar noves formes d'aprenentatge els ha suposat una motivació per continuar avançant. S'han adonat que entre tots poden aconseguir un objectiu comú i que cadascun d'ells és important per a l'equip. Són més conscients de les seues emocions i de les dels altres. Estan aprenent a expressar-les i a tenir-ne algun control. Entre altres aspectes han pres un primer contacte sobre la relació existent entre: pensament-sentiment-conducta. 
D'altra banda, hem d'aconseguir que els alumnes arriben a ser plenament conscients de les seues fortaleses personals, les seues capacitats, habilitats... i generalitzar-ho en diferents situacions quotidianes.

Un puntal fonamental de l'educació de l'alumne són els pares. Per això és molt important continuar insistint en la implicació i la col-laboració de la família en la comunitat escolar. Som conscients de les característiques de l'entorn d'aquests alumnes i per això encara hem de conjuntar més el treball de tots els docents i les famílies.

\section{Conclusions}

La realització d'aquest projecte «La melodia de la meua vida» ha estat possible gràcies a la disponibilitat atorgada pel centre escolar a l'hora de donar-hi suport i facilitar-ne la viabilitat. És un projecte que estableix les bases d'un aprenentatge fonamental per al present i el futur de cada individu. Aquest projecte és obert a la comunitat educativa i altres contextos educatius. Comparteix un dels principis de la responsabilitat social universitària (RSU) que advoca per una formació adreçada a estudiants preocupats per les injustícies, compromesos en accions concretes, capaços de contextualitzar el seu saber per solucionar problemes de la seua societat. A més de desenvolupar estratègies d'escolta activa i reflexiva, així com establir una comunicació comprensiva i empàtica. És a dir, un ciutadà promotor de la democràcia i la participació, on adquireix consciència de si mateix, del seu entorn i del seu paper del seu entorn (François Valleys, ¿Qué es la Responsabilidad Social Universitaria, p. 16).

\section{Referències}

Armstrong, T. (2006). Inteligencias Múltiples en el aula. Guía para educadores. Barcelona: Paidós Educador.

Bandler, R. i Grinder, J. (2005) La estructura de la magia 1. Lenguaje y terapia. Santiago de Chile: Cautro Vientos.

Bisquerra, R. (s. f.) en Rafael Bisquerra y GROP. Recuperado de: <http://www. rafaelbisquerra.com/es/competencias-emocionales/conciencia-emocional. html>.

Delors, J. (1996). Los cuatro pilares de la educación. Informe a la UNESCO de la Comisión internacional sobre la educación para el siglo XXI (Santillana/ UNESCO, pp. 91-103).

Gardner, H. (2005). Las inteligencias múltiples 20 años después. Revista de psicología y Educación, 1, 27-34. 
Gardner, H. (2012). Inteligencias Múltiples: la teoría en la práctica $\left(29^{\circ}\right.$ Edición). Barcelona: Paidós Ibérica.

Seligman, M. (2003). La auténtica felicidad. Barcelona: Ediciones B.S.A.

Valleys, F. (2008). ¿Qué es la Responsabilidad Social Universitaria? Julio 3, 2015, de Universidad Católica de Perú. Recuperado de: <http://www.unitru.edu.pe/Publicaciones/Jornada/Responsabilidad_Social_Universitaria. $\mathrm{pdf}>$.

Wilber, K. (1997). Breve historia de todas las cosas. Volumen I Barcelona: Kairós.

Yus Ramos, R. (2001). Educación Integral. Una educación holística para el Siglo XXI. Bilbao: Desclée De Brouwer. 